\title{
COMMUNICATIONS SERVICES IN BRITAIN
}

$\mathrm{I}^{\mathrm{N}}$ $\mathrm{N}$ his statement in the House of Commons on March 25, announcing further increases in postal charges, the Postmaster-General, Mr. Anthony Wedgwood Benn, said that over the next five years a deficit of more than $£ 120$ million was anticipated on the target set by the previous Government. The latest figures indicated a deficit of about $£ 32$ million by the end of March 1965 , about $£ 64$ million by March 1966, and about $£ 150$ million by March 1967. This was mainly due to the heavy dependence of the postal services on the manual collection, handling and delivery of the mail, which made it difficult to absorb rapidly rising costs, especially in the field of wages. The first and most important task was to improve the productivity and profitability of the postal services, and $\mathrm{Mr}$. Benn said that he had accordingly commissioned a fundamental and far-reaching examination of the problem by Messrs. McKinsey, the management consultants : a joint working party with the staff would work in parallel with the consultants. Mr. Benn said that he would also press forward with modernization, speed-up postal mechanization, and propare the way for its more effective application by firmly encouraging the use of standard envelopes and progressively extending the use of postal codes to Britain as a whole.

These and other measures could not yield the sub. stantial sums required to meet the deficit, nor would curtailment of services provide a satisfactory answer. The telecommunications services could not fill the gap and were themselves only just achieving their financial target. The Government, therefore, considered that an increase in postal charges was inescapable, and the extent of this increase had been decided in the light of the Joint Statement of Intent on Productivity, Prices and Incomes. The changes would come into force on May 17, and in a full year were estimated to yield about $£ 37$ million. When questioned, Mr. Benn admitted that the letter post was earning a profit but pointed out that, since the last increase, first-class letter costs had risen 25 per cent, and it was now estimated that the profitability of the firstclass letter would have fallen to about $£ 400,000$ by next year, whereas a 1 per cent increase in pay amounted to £2 million for the Post Office. He stated that the shortage of staff (2,000 postmen in the autumn in London alone) was becoming very acute, and this was not unconnected with remuneration. He also added that the finances of posts and telophones had always been separately treated, and that a White Paper* giving further details was now available.

This White Paper, after stating that a financial objective of 8 per cent had been agreed for the Post Office over the years 1963-68 and that this had been achieved on its net assets in each of the three years 1958-59 to 1960-61, points out that over the past ton years improvements in pay and conditions of service of staff cost the Post Office an extra $£ 83$ million, and price increases for goods and services another $£ 17$ million. Of this, $£ 83$ million was met by increased charges to the customer, $£ 12$ million by reduction of profit, and only $£ 5$ million by increased productivity; however, it was expected that increased productivity would provide $£ 2-3$ million a year. Letter traffic had increased in the first three-quarters of 1964-65 compared with the previous year, but parcel traffic was lower, and the decrease was expected to continue in 1965-66. Nevertheless, about 500 additional posts would

* Post Office Prospects 1965-1966. (London: H.M.S.O., 1965. Pp. 14.) (Cmnd. 2623.) 1s. 6d. net. be needed in 1965-66 to meet new housing development: the total staff in addition to just short of 23,000 sub-postmasters employed on an agency basis, at January 1, 1965, was 383,389 , compared with 375,427 on January 1,1964 . Income for 1964-65 was estimated at $£ 272$ million and in 1965-66 at $£ 310$ million, compared with expenditure of $£ 291$ million and $£ 308$ million, respectively. Of capital expenditure of $£ 14.9$ million in $1964-65$ and $£ 20.6$ million in $1965-66, £ 11 \cdot 1$ million and $£ 15.8$ million, respectively, were for accommodation services, $£ 1 \cdot 6$ million and $£ 1 \cdot 9$ million for plant, $£ 1.5$ million and $£ 2.1$ million for motor transport, and $£ 0.7$ million and $£ 0.8$ million for office machinery.

It had been decided, in co-operation with the Ministry of Technology and industry, to press ahead with the introduction of the standardized shape and sizes of envelopes which had now been agreed internationally and were needed to help mechanization. After consultation with the stationery trade a firm date would be fixed for the introduction of a higher tariff for non-standard envolopes. It had also been decided to introduce progressively a national postal coding system, which is essential to the full success of postal mechanization, and to make a major review of postal services offered to the public to see whether they can be better geared to modern conditions with charges more closely related to operating costs. New large buildings designed to take mechanization equipment were being constructed or planned and replacement of older offices would continue. Some fifty new post offices and more than twenty sorting offices werc expccted to start during the yoar, and the Joint Research and Development Group of the Post Office and the Ministry of Public Buildings and Works had evolved a range of standard designs for sorting offices and ancillary accommodation for smaller postal buildings which would reduce planning time and facilitate industrial methods of construction.

On telecommunications, the White Paper reports rapid growth in telephone and telex traffic, amounting to 17 per cent per annum in inland telephone trunk calls, 8.9 per cent in local calls, 25 per cent in telex calls and about 15 per cent in overseas calls-both telex and telephone. There was little change in the number of inland exchange operators during the year, as increases which would have been required were offset by conversion to automatic working and the extension of subscriber trunk dialling. The engineering, construction and maintenance staff increased by about 6,000 to nearly 107,000 and is expected to increase by 3,500 in $1965-66$. Nevertheless, it is admitted that the telephone service, especially in London and the South East, is not everywhere as good as it should be, traffic having in some places outstripped capacity.

The income of the telecommunications service in 1964 65 is estimated at $£ 368$ million and in $1965-66$ at $£ 399$ million, compared with expenditure of $£ 334$ million and $£ 364$ million, respectively-the return on capital being 8.2 per cent and 7.9 per cent. Capital expendituro is estimated at $£ 177.9$ million and $£ 209.3$ million, respectively. About 8,000 trunk circuits will be added to the system during the year, telephone switching equipment installed at some 155 new exchanges, and 330 existing exchanges oxtended. It is planned to provide an additional 600,000 lines in the local cable network connecting subscribers' premises with telephone exchanges, and it is expected that orders for about $1,090,000$ connexions will 
be met during $1965-66$, bringing the total connexions at March 31,1966 , to almost 6.4 million, and the number of telephones, including extensions, to about 10.75 million. At December 31, 1964, the waiting list was steady at almost 46,000: plans are being reviewed in the context of virtually eliminating the waiting list by March 1966 . The telex service will have more than 14,500 lines at the beginning of 1965-66, and about 3,200 will be added during the year, while the Datel Service, which provides facilities for data to be sent to computers over telephone and telegraph circuits, will be expanded to meet customers' needs.

On development plans, the White Paper states that the automatization programme continues to make good progress towards completion by 1970; by March 1966, when only about 320 manual exchanges will remain, automatic service should be available to 94 per cent of subscribers, about 60 per cent of whom will have trunk dialling facilities. Building work on the operational part of the Post Office Tower, London, has been completed, and the first micro-wave radio link will be brought into use early in 1965-66. It is expected that the Tower will be open to the public early in 1966. Elcctronic equipment designed for use in small exchanges has been installed at Leamington Spa and Peterborough for trial in 1965, and a larger electronic exchange being installed at Leighton Buzzard should come into public service early in 1966 . Mechanization and decentralization of the operating work of overseas telegraphs continue to ease staffing problems and improve the standard of service. The introduction of telex services with Burma, Egypt, Dakar, Macau, Libya, Turkey, Cyprus and Syria is planned, while International Subscriber Dialling will be extended to Canada, New Zealand, Australia, Spain and Portugal. The first section of the Commonwealth South-east Asia cable, linking Singapore with Sabah, was opened in January 1965, and the section from Sabah to Hong Kong was expected to be ready for service in March 1965.

Under the international agreements signed in August 1964 embodying arrangements for creating a commercial communications satellite system, the Post Office now shares in the ownership of the space segment of the world satellite system and its management, through a seat on the international committee in Washington which controls the project. This committee is planning a satellite system to give the elements of a world system in the latter part of 1967. Meanwhile, a single synchronous satellite, designed to carry, on an experimental basis, an element of commercial telephone traffic and probably television, was planned to be launched this spring, and the Earth station at Goonhilly Down was being developed to take part in this project.

When the White Paper was discussed in the House of Commons on March 30, Mr. Wedgwood Benn commented that investment in postal mechanization this year would be nearly $£ 2$ million, rising to $£ 4$ million in two years, and to more than $£ 6$ million in the following two years. The parcel-sorting machine had been perfected and would be installed in sorting offices as they were rebuilt. The final prototype of the high-speed letter-sorting equipment would have field trials at Norwich, where the first fully automated sorting office would be established. The postal coding system of six characters tested there would be applied throughout Britain, but it had been found impracticable to have the same code for the subscriber trunk dialling area and the postal area. He oxpected electronic exchangos to come into more general use by 1968 and commented that the Government wanted to ensure a fair return for the research and development work in designing equipment manufactured for the telecommunications industry. The possibility of using the Datel Service to oxtend the use of computers by British industry was also being studied, and the Post Office had just ordered $£ 2.5$ million worth of computers for its own use. In replying on the debate, the Chief Secretary to the Treasury, Mr.
J. Diamond, said that the Datel Services would go to the development districts and wherever there was need for them. The Government was most anxious to provide these services and to encourage manufacturers everywhere to modernize their plant and attitudes.

Disregarding that part of the debate which was concerned with how far the present deficit is the fault of the inaction of Government, the debate directed attention to some realities of the situation which are pointedly ignored in the White Paper and by the Postmaster-General in his statement. The new charges will add appreciably to industrial and commercial costs and, in so far as the Post Office is also a social service (as was recognized in the debate), to social costs also. This latter aspect is one that perhaps calls for more consideration than it appears to receive in the White Paper, and it is one that, moreover, tends to be overlooked in mechanization. While the decision to press on with standardization of sizes of envelopes is undoubtedly right, it does to some extent represent an intrusion on the individual, and probably imagination and understanding are nowhere more needed than where such developments impinge on what is some thing of a personal and social service. Furthermore, it is at least possible that such considerations may provide a key to the improvement of efficiency and standards of service as well as reduction of costs in certain districts. It does not follow that the same frequency of collection and delivery is necessary or even desirable everywhere.

What matters more is the reliability and trustworthiness of the service, and where the Postmaster-General and the White Paper are most at fault is in refusing to admit that over the past two decades at least the postal service has visibly deteriorated. This was emphasized in the debate, and there can be few who are without personal experience of excessive delays in delivery and ineptitude that were scarcely imaginable in earlier years. For all the improvements in speed of communication over the past half century, the postal service is slower and more uncertain than it was when the present century opened. One reason for welcoming the introduction of a national postal coding system is that it should put an end to the inconvenience and delays that the public suffers from the Post Office practice of using, in effect, certain towns as 'code numbers' - especially when they are in different counties from that in which the smaller town or village addressed is located. However good the present administrative reasons for this practice, the Post Office should recognize that addresses are not used solely for postal purposes, and where they deliberately introduce another county into an address the onus of avoiding confusion and error lies fair and square on the postal authorities.

There is, however, one aspect of the increased charges which particularly affects the scientist and technologist. Learned societies will be seriously affected by the consequent increased costs of distribution of notices of meetings and of periodicals. Few, if any, in Britain are likely to benefit from the larger rebates offered for bulk postings of 250,000 or more printed papers, and to many of the smaller societies, even a small increase may make all the difference. While it might be no bad thing if the multiplication of scientific and technical pericdicals were checked and if some ceased publication or merged with other periodicals, this is not the method to achieve rationalization-though it might provide the stimulus. There is room for thought as to the effect on scientific communication, and the scientific and technical community might well consider what steps it could take from within to ease the situation.

Standardization of envelopes will presumably also apply here, though this is not made clear in the White Paper. On this it might be observed that before a higher tariff is fixed for shapes and sizes which do not conform to standard, much longer notice must be given than Mr. Wedgwood Benn's statement seemed to suggest. It is not only stationers who are affected. If periodicals in transit 
are also concerned, the format of periodicals may likewise be involved, and it was observed in the debate that we may have to fix a date of five years hence rather than two for introducing the new standards. On March 30, Mr. Benn himself suggested that the function of the Post Office to-day could only be understood if it were regarded as a 'Ministry of Communications'. Nevertheless, the White Paper and Mr. Wedgwood Benn's own statements suggest that he needs to give much clearer and unprejudiced thought to the indirect as well as the direct effect of his proposals on the work of the Post Office alike as a social service and as a means of communication. However justified the new charges may be at the moment, it should be a primary objective of policy to reduce them at the earliest possible moment that the technical developments offer.

\section{VACUUM BREAKDOWN}

D URING April 12-13 a working party met at the University College of Swansea to discuss research now being undertaken on the basic processes underlying the phenomenon of the breakdown of vacuum insulation. This working party was organized jointly by Mr. W. F. Gunn, of the Atomic Weapons Research Establishment, and Dr. J. Dutton, of the Department of Physics, University College of Swansea. The invited participants numbered about twenty and comprised those actively undertaking or closely concerned with research in this subject, and included scientists from France, Switzerland, the United States, and Britain. The procedure differed from that usually followed in conferences in that there were four sessions, each containing one short paper only, the function of which was to stimulate discussions on particular facets. This procedure proved to be entirely satisfactory in that discussion was free, vigorous and extremely helpful.

After welcoming the working party, Prof. Llewellyn Jones (University College of Swansea) outlined the general phenomena of vacuum breakdown and surveyed the present theories of the processes and lines of investigation. The first session was devoted to breakdown processes in small gaps at ambient pressures of $10^{-5}$ torr, and a paper by Dr. W. D. Owen (Atomic Weapons Research Establishment) showed how breakdown would follow from the release of adsorbed gas molecules from electrode surfaces under electron bombardment by pre-breakdown field-induced currents. The ensuing discussion dealt with the dependence of the processes on the surface state, and this led to quantitative estimates of the size $\left(\sim 10^{-11} \mathrm{~cm}^{2}\right)$ of electron emitting areas.

The next session was devoted to a detailed study of the initiation, growth and destruction of microscopic metal protuberances. A detailed mathematical analysis of the stability of a local disturbance on a plane surface in an electric field was given by Dr. F. Rohrbach (CERN). This showed how the growth and stability of a protuberance were dependent on surface tension and other physical properties of the metal. This paper led to exciting discussions on the feasibility of ever obtaining perfectly plane surfaces in electric fields, and the implications of this in various electronic applications were discussed. It was shown from the theory that a particularly effective surface for minimizing cold emission could be obtained by a prepared surface of aluminium oxide with micro- scopic protuberances of almost $\Omega$-shaped section. Electrodes with this type of surface had been found in practice to be able to withstand high electric fields in vacuum in large gaps.

In the third session, Mr. A. Maitland (University of St. Andrews) gave a survey of some of the problems associated with electron beams and their role in vacuum breakdown. In the following discussion, attention centred on the form and stability of observed discharges. The final session was devoted to breakdown in high vacuum ( $\leqslant 10^{-9}$ torr). Mr. J. Beynon (University College of Swansea) described work directed to the evaluation of the effect of adsorbed gas molecules in ultra-high vacuum breakdown. Ho showed how their removal from the electrode surfaces by heat-treatment reduced the incidence of the usual prebreakdown current pulses and associated release of gas, and thus led to almost stable conditions. These observations were consistent with the view that pre-breakdown (Fowler-Nordheim) cold emission from emitting sites of very small area $\left(\sim 10^{-10}-10^{-11} \mathrm{~cm}^{2}\right)$, which could well be microscopic protuberances discussed earlier, could release minute quantities of adsorbed gas which was detected by ionization gauges.

In summing up the meeting, Prof. Llewellyn Jones attempted to draw an overall and consistent picture of the succession of processes constituting $a$ mechanism of vacuum breakdown. This involved a full discussion of the nature and stability of surfaces in general, and it was agreed that the development of surface protuberances in electric fields could well provide the emitting areas which would be consistent with the areas deduced from the observed pre-breakdown field emission currents. These currents could then set in train other processes such as desorption of gas molecules from electrode surfaces to make possible gas ionization and current amplification. The general opinion was that the ambient atmosphere necessary to produce this amplification in the experiments discussed seemed more likely to be due to desorbed gas rather than to metal vapour from the explosion of protuberances caused by high-current density field emission.

The meeting, which was greatly appreciated by those present, ended with accounts of the future research programmes which the various laboratories proposed following as well as of those lines of approach which appeared most promising.

\section{EXPERIMENTAL TAXONOMY OF FLOWERING PLANTS}

A SYMPOSIUM on "The Experimental Taxonomy of Flowering Plants" was held at the Linnean Society on March 5. Prof. D. H. Valentine introduced the symposium and took the chair at the morning session; Dr. P. R. Bell, vice-president of the Society, took the chair in the afternoon.

The first paper, on "Fruit Variation in the Carex glareosa Complex", was by Dr. G. Halliday and Mr. A. O. Chater, of the University of Leicester. They described in detail the disjunct circumpolar distribution of this group of sedges, and pointed out that its components, C. glareosa Wahlenb. and C. marina Dewey, are commonly regarded as being specifically distinct. The main dis. tinguishing character is in the shape of the fruit, the former species having fusiform fruits, and the latter shorter, broader and more or less beaked fruits, but intermediate types occur. Careful examination of an extensive range of herbarium material, some of it collected 